\title{
The Khaung Daing hot spring (Inle lake, Southern Shan State, Myanmar): development opportunities and challenges
}

\author{
Elisa Sacchi ${ }^{1}$, Sergio Comizzoli ${ }^{1}$, Eloisa Di Sipio ${ }^{2}$, Viviana Re $^{1, *}$, Marco Rotiroti $^{3}$, \\ Massimo Setti ${ }^{1}$, and Myat Mon Thin ${ }^{3}$ \\ ${ }^{1}$ Dep. of Earth and Environmental Sciences, University of Pavia, 27100 Pavia, Italy \\ ${ }^{2}$ Geologist, Erlangen, Germany \\ ${ }^{3}$ Dep. of Earth and Environmental Sciences, University of Milano-Bicocca, Milan, Italy \\ ${ }^{4}$ Dep. of Physics, University of Mandalay, Myanmar
}

\begin{abstract}
Located on the north-western border of the Inle lake basin, the Khaung Daing hot spring outflows at ca. $70^{\circ} \mathrm{C}$. Temperature at depth, calculated with chemical geothermometers is probably less than $150^{\circ} \mathrm{C}$, therefore classifying it as a medium-low enthalpy geothermal resource. Geochemical and isotopic results also demonstrate that the hot spring is fed by local groundwater, equilibrated with the carbonate rocks but without isotopic exchange with the matrix. Trace elements, particularly As (119 $\mu \mathrm{g} / \mathrm{L})$, display high concentrations, raising some concern about potential environmental and health effects.
\end{abstract}

\section{Introduction and study area}

The Inle Lake basin (Southern Shan State, Myanmar) is located in the Shan Plateau, belonging to the Sibumasu block [1], and mainly made of Permo-Triassic carbonates. The stratigraphic sequence of the Southern Shan State, reaching up to $1000 \mathrm{~m}$ in thickness, includes the Thitsipin Limestone Fm (conglomerates, laminated calcareous shale, fined grained calcareous sediments, calcareous sandstones and massive cherty wackestones, sometimes partially dolomitized), and the overlying Nwabandgyi Dolomite Fm (calcareous conglomerates and sandstones, dolomitic and bioclastic wackestone and turbiditic dolomitic mudstone) [2].

The area is strongly affected by the recent tectonic activity, related to the movement of the eastern Himalayan syntaxis [3]. The Inle lake watershed developed along a right-lateral strike-slip fault running parallel to the Sagaing fault, a major continental transform fault between the India and the Sunda plates, and is bordered on the east side by the so-called Taunggyi normal fault. The rhombic shape of the basin is characteristic of a pull-apart structure $[4,5]$.

The Khaung Daing hot spring (Fig. 1) outflows to the NW of the Inle Lake, at the foothills of the Western Range (Fig. 1) (long. 47Q 0279103; lat. 2282517). Three main

* Corresponding author: viviana.re@unipv.it 
outflows are present [6]: (i) two small springs that are merged together to feed two pools used by local residents as public baths; (ii) a larger outflow representing a holy site, where outflowing water is collected to feed a tourist spa; and (iii) a small pool located more uphill, not presently used. Previous investigation in the area mostly focused on lake water quality and hydrodynamics [7] and on surface-groundwater interactions [8]. A first hydrochemical and isotopic reconnaissance study of the hot spring [6] indicated an outflow temperature of about $70^{\circ} \mathrm{C}$, a slightly acidic $\mathrm{pH}$, an electrical conductivity of about $1150 \mu \mathrm{S} / \mathrm{cm}$, a low Eh (about $-105 \mathrm{mV}$ ) and a $\mathrm{Na}-\mathrm{HCO}_{3}$ hydrochemical facies. The water stable isotope composition ( $\delta \mathrm{D}$ and $\delta^{18} \mathrm{O}$ ), close to the Yangon Meteoric Water Line, agrees with the mean composition of the lake water during the rainy season, suggesting that the hydrothermal circuit could be recharged by local precipitation [6]. These preliminary results indicated that this hydrothermal water is likely related to deep meteoric and ground water circulation within a fault zone, in a region characterized by an elevated geothermal gradient. Nevertheless, no information was available about its geothermal potential and trace element content. The aim of this contribution is to provide this information to support a sustainable development of this resource.

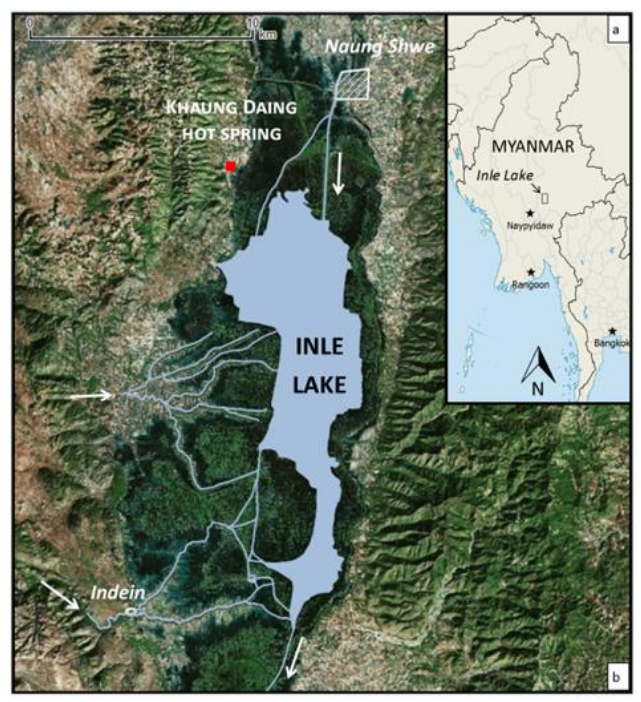

Fig. 1. a) Location of Inle lake in Myanmar; b) Location of the Khaung Daing Hot Spring in the lake catchment. White arrows indicate the surface water flow direction.

\section{Methods}

During a campaign carried out in February 2018 to collect samples of lake, river and ground waters from the watershed, one sample of the hot spring was also collected. Temperature, Electrical Conductivity (EC), $\mathrm{pH}$ and Eh were measured in the field with a multiparameter probe (WTW 340i), and alkalinity was measured using the HACH Alkalinity Test Kit (Model AL-AP). A sample aliquot was filtered to $0.45 \mu \mathrm{m}$ and acidified to $\mathrm{pH} 2$ with ultrapure hydrochloric acid. In the laboratory, samples were analyzed for alkalinity by titration, whereas the ionic contents were determined by ion chromatography at the University of Torino, Italy. The analytical error was estimated from electro-neutrality balances to be less than $\pm 5 \%$.

Total phosphorus content was determined with the Molybdenum blue method [9] on an unfiltered sample aliquot previously subject to persulfate microwave digestion to convert all $\mathrm{P}$ in orthophosphate [10]. Dissolved Fe, Mn and As contents were analyzed on the 
filtered sample by GF-AAS (Perkin Elmer AAnalist 600). Dissolved silica content was determined by the silicomolybdate method using a HACH spectrophotometer DR2800 (method \#8185). Stable isotopes of the water molecule were determined by WavelengthScanned Cavity Ring-Down Spectroscopy (WS-CRDS) at ISO4 in Italy. Results are reported in the delta $(\delta)$ notation vs V-SMOW, with an uncertainty $(2 \sigma)$ of $\pm 0.2 \%$ for $\delta^{18} \mathrm{O}$ and $\pm 1 \%$ for $\delta^{2} \mathrm{H}$. Saturation indices with respect to the main mineral phases were calculated using the PHREEQC software [11].

\section{Results and discussion}

\subsection{Hydrochemical and isotopic characteristics}

Major ion composition of the hot spring water is in agreement with previous data $[6,8]$ : the temperature is $69.2^{\circ} \mathrm{C}$, pH is slightly acidic (6.6) and the EC is $1162 \mu \mathrm{S} / \mathrm{cm}$. The measured Eh is slightly higher than previously measured $(-30 \mathrm{mV})$, in agreement with a higher concentration of dissolved sulfate $(62.1 \mathrm{mg} / \mathrm{L})$ and calcium $(46.2 \mathrm{mg} / \mathrm{L})$. Overall, water can be classified as $\mathrm{Na}^{-\mathrm{HCO}_{3}}$ type.

Dissolved silica $\left(\mathrm{SiO}_{2}=51.7 \mathrm{mg} / \mathrm{L}\right)$, reported for the first time, seems high for water circulating in carbonate rocks only, suggesting the presence of silicates as well. Indeed, mineralogical data on the outcrops of the Western Range, close to the hot spring outflows, indicate the presence of Quartz, Muscovite and Kaolinite, together with Goethite [6]. Trace elements $(\mathrm{P}=64.4 ; \mathrm{Fe}=156 ; \mathrm{Mn}=82 ; \mathrm{As}=119 \mu \mathrm{g} / \mathrm{L})$ also display high concentrations, raising some concern about potential environmental and health effects.

Concerning the origin of $\mathrm{As}$, the a) low $\mathrm{Cl}, \mathrm{b}$ ) negative $\mathrm{Eh}, \mathrm{c}$ ) acidic $\mathrm{pH}$, d) isotopic composition indicating no evaporation (see below) and e) co-presence of $\mathrm{P}, \mathrm{Fe}$ and $\mathrm{Mn}$ suggest that As mobilization in the hot spring water is likely the reductive dissolution of Fe-oxides [12].

The isotopic composition $\left(\delta^{18} \mathrm{O}=-7.19 \% ; \delta^{2} \mathrm{H}=-51.34 \%\right.$ ) falls close to the Yangon Meteoric Water Line and agrees with the mean composition of groundwater samples unaffected by evaporation in the area $\left(\delta^{18} \mathrm{O}=-6.98 \pm 0.71 \% ; \delta^{2} \mathrm{H}=-49.36 \pm 4.12 \%\right.$ o $)$ [8].

\subsection{Geothermometry}

Outflowing water falls in the field of peripheral waters [13] as bicarbonate ions account for more than $88 \%$ of the sum of anions, expressed in $\mathrm{mg} / \mathrm{L}$. These waters are often at equilibrium and may be used to predict subsurface properties [14].

Only few chemical geothermometers are available for low enthalpy systems located in sedimentary environments, since most have been calibrated for high temperature fluids circulating in crystalline rocks [15]. In addition, plotting the Khaung Daing water composition on the Giggenbach ternary diagram [16], this falls in the field of immature waters at the transition to partially equilibrated waters. In this case, most cation-based geothermometers are not suitable to provide indication of the temperature at depth. We therefore attempted to estimate the reservoir temperature using the available chemical geothermometers for sedimentary formations combined to modelling [15].

First, the main saturation indices with respect to mineral phases potentially present at depth were calculated (Table 1). Other aluminosilicate phases are or could be present (e.g. Muscovite) but unfortunately Al could not be analyzed and SI calculated. Based on these SI, water is in equilibrium with Quartz and Calcite but below saturation with Chalcedony, Dolomite, Fluorite and Anhydrite. 
Table 1. Main saturation indices (SI) calculated with PHREEQC.

\begin{tabular}{|c|c|c|c|c|c|c|}
\hline Mineral & Calcite & Dolomite & Quartz & Chalcedony & Anhydrite & Fluorite \\
\hline SI & 0.13 & -0.53 & 0.02 & -0.29 & -1.89 & -0.13 \\
\hline
\end{tabular}

Secondly, we selected the chemical geothermometers that could be applied to calculate reservoir temperatures in our system. The Ca-Mg and $\mathrm{SO}_{4}-\mathrm{F}$ geothermometers have been specifically calibrated in carbonate-evaporitic environments [17]. They were used together with the dissolved silica geothermometers $\left(\mathrm{SiO}_{2}\right.$-Quartz and $\mathrm{SiO}_{2}$-Chalcedony). The estimated temperatures (Table 2) are not in agreement. The $\mathrm{SO}_{4}-\mathrm{F}$ couple provides exceedingly high temperatures $\left(1263^{\circ} \mathrm{C}\right)$, likely because sulfate ions derive from the partial oxidation of sulfides at the outflow $(\mathrm{Eh}=-30 \mathrm{mV})$. Also, the temperature provided by the $\mathrm{Ca}-\mathrm{Mg}$ equation is based on water equilibration with calcite and dolomite, but strongly depends on the order-disorder degree of the dolomite in the host rock. Indeed, when using the equation accounting for a partially ordered dolomite, a more reasonable estimate is obtained $\left(140^{\circ} \mathrm{C}\right)[18]$.

Table 2. Applied chemical geothermometers and temperatures calculated in ${ }^{\circ} \mathrm{C}$.

\begin{tabular}{|c|c|}
\hline Geothermometer & Temperature \\
\hline $\mathrm{SiO}_{2}$-Quartz [19] & 103.3 \\
\hline $\mathrm{SiO}_{2}-\mathrm{Chalc}[19]$ & 73.6 \\
\hline $\mathrm{Ca}-\mathrm{Mg}[17]$ & 279.9 \\
\hline
\end{tabular}

Finally, we simulated a theoretical increase in the temperature of the water until saturation with Dolomite is reached. This is based on the observation that dolomite outcrops are present to the NW of the study area, along the roadside from Heho to Shwenyaung, and that mineralized groundwater uprising along the fractures is of $\mathrm{Mg}(\mathrm{Ca})$ $\mathrm{HCO}_{3}$ type [8]. The simulation indicated that dolomite saturation occurred at a temperature of $99^{\circ} \mathrm{C}$, thus in good agreement with that provided by the $\mathrm{SiO}_{2}$-Quartz geothermometer and in the range of the Ca-Mg geothermometer (considering partially ordered Dolomite).

\section{Conclusions}

This contribution provides addition knowledge on the origin of the Khaung Daing Hot Spring and on the geochemical processes governing its composition. Results suggest that the spring is fed by groundwater circulating in the watershed, equilibrated with the carbonate rocks but with no isotopic exchange with the matrix. Temperature at depth is unlikely to exceed $150^{\circ} \mathrm{C}$, although present estimates are affected by a high degree of uncertainty. This is mostly due to the lack of $\mathrm{Al}$ data, not permitting to calculate the saturation with respect to aluminosilicates and test other geothermometers; and to the lack of knowledge about the degree of ordering of dolomite, assumed as the main mineral constituting the reservoir host rock. These uncertainties should be investigated in the future in order to support an adequate development of this resource. Overall, this hydrothermal system, characterized by an outflow temperature of $\sim 70{ }^{\circ} \mathrm{C}$, can be considered as a medium-low enthalpy geothermal source (i.e. with fluids at temperatures below $150{ }^{\circ} \mathrm{C}$ ), 
and classified as orogenic belt type (hydrothermal) - CD2 type [20]. Hence it is suited to meet, either directly or using heat exchangers and pumps, the thermal requirements both for air conditioning of residential and industrial buildings (heating/cooling, ground source heat pumps). It can be used also for different agricultural-industrial processes (e.g. therapeutic uses including clay maturation in pelotherapy, greenhouses, aquaculture, processing and transformation of plant and animal products) [21, 22, 23], subject to an adequate assessment of the hydrogeology of the spring. Attention should be given to the potential adverse health effects of the high As content, since skin adsorption during bathing could be a relevant exposure pathway for the population and the spa workers.

\section{References}

1. I. Metcalfe, K.P. Aung, Gondwana Res, 26, 1159-1172 (2014)

2. T. Oo, T. Hlaing, N. Htay, J Asian Earth Sci, 20, 683-689 (2002)

3. R.A.J Robinson, C.A. Brezina, R.R. Parrish, S.A.M. Horstwood, N.W. Oo, M.I. Birda, M. Thein, A.S. Walters, G.J.H. Oliver, K. Zaw, Gondwana Res, 26, 112-121 (2014)

4. Y. Wang, K., Sieh, S.T. Tun, K.Y. Lai, T. Myint, J Geophys Res Solid Earth, 119, 3767-3822 (2014)

5. S. Crosetto, I.M. Watkinson, S. Min, S. Gori, E. Falcucci, N. Le Ngal, J Asian Earth Sci, 156, 207-225 (2018)

6. E. Sacchi, V. Re, M. Setti, M.M. Thin, E. Di Sipio. Procedia Earth Planet, 17, 750-753 (2017)

7. M.M. Thin, E. Sacchi, M. Setti, Isot Environ Health S, 52, 455-467 (2016)

8. V. Re, M.M. Thin, M. Setti, S. Comizzoli, E. Sacchi, Appl Geochem, 92, 82-93 (2018)

9. J. Murphy, J.P Riley, Anal Chim Acta, 27, 31-36 (1962)

10. P.J. Johnes, A.L. Heatwaite, Wat Res, 26/10, 1281-1287 (1992)

11. D.L. Parkhurst, C.A.J. Appelo Water-Resources Investigations Report 99-4259, 310 (U.S. Geological Survey, 1999)

12. P. Ravenscroft, H. Brammer, K. Richards, Arsenic Pollution: A Global Synthesis. (Wiley-Blackwell, Chichester, 2009)

13. W.F. Giggenbach, in: Application of Geochemistry in Geothermal Reservoir 119-142 (UNITAR/UNDP, 1991)

14. L. Marini, http://www.appliedgeochemistry.it/doc/Geochemistry Marini.pdf (2004)

15. M. Blasco, M.J. Gimeno, L.F. Auqué, Sci Total Environ, 615, 526-539 (2018)

16. W.F. Giggenbach, Geochim. Cosmochim Acta 52, 2749-2765 (1988)

17. G. Chiodini, F. Frondini, L. Marini, Appl Geochem. 10, 337-346 (1995)

18. G. Vespasiano, C. Apollaro, F. Muto, E. Dotsika, R. De Rosa, L. Marini, Appl Geochem, 41, 73-88 (2014)

19. R.O. Fournier, Geothermics, 5, 41-50 (1977)

20. I.S. Moeck, Renew Sust Energ Rev, 37, 867-882 (2014)

21. P.L. Younger, Energies, 8, 11737-11754 (2015)

22. D.E. Bruno, E. Di Sipio, A. Galgaro, G. Lombardo, E. Destro, S. D’Arpa, V.F. Uricchio, A. Manzella, Energ Effic, 10, 639-655 (2017)

23. F. Veniale, E. Barberis, G. Carcangiu, N. Morandi, M. Setti, M. Tamanini, D. Tessier, Appl Clay Sci, 25, 135-148 (2004) 